\title{
Frutos y vegetales aderezados
}

\author{
Por M. J. Fernández Díez. \\ Instituto de la Grasa y sus Derivados (CSIC.).- Avda. Padre García Tejero, 4. 41012 - Sevilla
}

\section{RESUMEN}

Frutos y vegetales aderezados

Se revisan los principios generales en que se basa la tecnologla de productos vegetales aderezados y fermentados, y se describen los procedimientos industriales que han alcanzado mayor difusión en el mercado internacional.

Se definen las directrices fundamentales para orientar la investigación en otros productos vegetales de posible interés para el desarrollo del sector agroalimentario, estableciéndose como objetivos básicos de la misma el conocimiento de la composición química de la materia prima, el estudio de la secuencia natural y específica para cada elaboración, de los microorganismos responsables del proceso, la selección de variedades adecuadas y la fijación de intervalos óptimos de recolección.

PALABRAS-CLAVE: Aderezo - Fermentación - Fruto - Información (articulo) - Vegetal.

\section{SUMMARY}

Pickled fruits and vegetables.

A review was made on the general principles in which the technology of pickled and fermented vegetable products is based, as well as a description of the industrial procedures which have reached a wider difussion in international trade.

Fundamental lines to orient research on other vegetable products, which show a certain interest to spread the pickling industry, were defined, and their basic objectives were established: a) knowledge of the chemical composition of the raw material; b) study of the natural sequence of the microorganisms which are responsible for the process; c) selection of the suitable varieties of the product; and d) establishment of the optimum harvesting time.

KEY-WORDS: Fermentation - Fruit - Information (paper) - Pickling - Vegetable.

\section{INTRODUCCION}

Para los consumidores y especialistas en la materia, se presentan con frecuencia problemas semánticos para la correcta interpretación de los términos o palabras clave que se van a utilizar en este trabajo.

Según el Diccionario de la Real Academia Española de la Lengua, el verbo aderezar tiene el significado, excesivamente amplio, de "guisar, condimentar, sazonar los alimentos". Pueden, por tanto, incluirse dentro de los productos aderezados, con rigurosidad gramatical, una fabada asturiana, un asado de carne y unos pepinillos en vinagre.
Sin embargo, en Tecnología de Alimentos, los productos aderezados se asocian, en primer lugar, con el término vegetal, y a continuación con la presencia de un ácido comestible. Si este último es el ácido acético del vinagre, puede emplearse el vocablo encurtido, e incluso el de variante.

La palabra anglo-norteamericana "pickle", la más próxima en significado a la española aderezo, responde, según el Diccionario de Webster, a la definición de "un vegetal conservado en una salmuera, vinagre, - solucción aromatizante". Pederson (1) define e producto aderezado como aquél conservado y aromatizado en una salmuera con ácido comestible, tal como el vinagre. Luh y York (2) lo especifican como aquel producto en que se añade, para su conservación, un ácido comestible, diferenciándolo del producto fermentado en el que, conservándose igualmente, al menos en parte, por el ácido, éste se ha producido por un proceso biotecnológico, en lugar de ser añadido.

Quizás el concepto genérico más útil para agrupar tecnologías afines, en cuanto a principios generales de elaboración, y en lo referente a características sensoriales del producto final, sea definir como producto aderezado todo aquel, de origen vegetal, en que la preparación se lleva a efecto mediante un ácido comestible, añadido o producido "in situ" por fermentación, y en que la conservación se debe, al menos parcialmente, a la presencia de dicho ácido.

Como no hay regla sin excepción, en el caso de la aceituna de mesa, el término aderezada ha llegado a adquirir, en la normativa vigente, un carácter diferenciador de tecnologías, distinto y atípico, aplicándose en general a los frutos tratados con lejías alcalinas, como fase previa a la de fermentación.

Cierta confusión se produce también entre los tecnólogos al aplicar los conceptos vegetal y fruto, pues si bien botánicamente el primero engloba al segundo, es frecuente asociar este último con los productos habitualmente utilizados como postre en las comidas, $\theta$ incluir en los textos como vegetales aderezados a los pimientos y pepinillos, por ejemplo, los cuales son típicos frutos en el sentido literal, de la palabra. Aquí de nuevo la aceituna de mesa 
constituye una excepción, y se cataloga siempre donde le corresponde.

Una vez fijada la idea de que el rasgo fundamental que caracteriza a los productos aderezados es la presencia de un ácido comestible, por adición o fermentación, puede añadirse que, aunque sin carácter general, en su elaboración desempeña frecuentemente un papel importante el cloruro sódico, y en menor grado las hierbas aromáticas y especias, así como sus extractos naturales o sintéticos. El primero actúa como coadyuvante en la conservación, y tanto él como los demás son factores integrantes que contribuyen a las características organolépticas del producto final.

Un proceso térmico de pasterización o esterilización, optativo o necesario según los casos, completa a grandes rasgos la panorámica general de la biotecnología del aderezo la cual puede aplicarse, en principio, a todos los vegetales, con ligeras variaciones de uno a otro. De aquí que la investigación realizada hasta la fecha, y consiguientemente sus resultados, sirvan como guía orientativa muy segura para futuras especialidades, que constituyen un reto para las nuevas generaciones de científicos y tecnólogos que trabajan en el área de Agroalimentación.

Como indica Pederson (1) casi todas las sustancias vegetales, como hojas, tubérculos, semillas y frutos, pueden aderezarse y suministrar suficientes nutrientes para el crecimiento de los microorganismos responsables de una fermentación. Remolachas, nabos, cebollas, coliflores, coles de Bruselas, habichuelas verdes, guisantes frescos, tomates y lechugas (3) se han elaborado así con frecuencia, e incluso algunos de estos productos han alcanzado cierta importancia comercial en determinados países. Woodroof (4) describe distintos aderezos de frutos, como melocotones, peras y uvas, mediante el empleo del vinagre y sustancias aromatizantes, que manifiestan una cierta popularidad en Estados Unidos de Norteamérica.

Sin embargo, y esta es norma general en Tecnología de Alimentos, los procedimientos que verdaderamente han prosperado hasta la fecha, son relativamente reducidos en número, y su tecnología, desarrollada desde principios del siglo actual, se basa en costumbres culinarias ancestrales, transmitidas por tradición familiar. Así, es frecuente encontrar referencias a textos muy antiguos, anteriores en varios siglos a la Era Cristiana, en que se describen métodos artesanales para aderezar coles ácidas (sauerkraut) pepinillos y aceitunas; $y$ son precisamente estos tres productos los que actualmente acaparan el mercado internacional, y para los que se han obtenido avances más importantes en su producción industrial normalizada, con grados de calidad muy aceptables.

Dado que la tecnología de la preparación de aceituna de mesa se ha tratado ampliamente en una reciente monografía, se dedica especial atención a las otras dos elaboraciones destacadas, se hace referencia como caso especial al pimiento rojo dulce que, como industria subsidiaria de la de aceituna ha recabado en época todavía reciente el interés de los investigadores $y$, finalmente, se resume la información general de utilidad, referente a la preparación de otros productos aderezados, de creciente importancia comercial.

\section{COLES ACIDAS (sauerkraut).}

La preparación de este producto, cuya elaboración artesanal en Europa puede muy bien remontarse al menos cuatro milenios, ha dado lugar a una importante industria alimentaria en diversos países del viejo Continente y en Estados Unidos de Norteamérica. Su tecnologia, desarrollada en las primeras décadas del siglo actual, ha sido excelentemente resumida por Vaughn (5) y Cruess (3).

Los repollos, procedentes de variedades cuidadosamente seleccionadas, una vez recolectados en el estado de madurez adecuado, se almacenan en la fábrica, bien amontonados, bien en contenedores especiales, a temperatura uniforme controlada, que debe ser al menos de $20^{\circ} \mathrm{C}$, y durante el tiempo necesario para que el vegetal se marchite lo suficiente, en su parte externa, como para permitir la separación de las hojas periféricas, y las más verdes, sin que se produzca la rotura del resto. Parece ser que este tipo de reposo facilita también el troceado posterior en tiras, que se realiza mecánicamente, tras el escogido y selección.

Una vez realizadas estas operaciones, el material ya partido se conduce, mediante cintas transportadoras, a los tanques de preparación, construidos de madera, que puede estar o no revestida de parafina, hormigón con revestimiento plástico, o de este último material.

La fermentación ha de llevarse a cabo en presencia de cloruro sódico (entre 2 y $3 \%$ con respecto al peso de coles), cuyas principales misiones son: facilitar la extracción por ósmosis del agua presente en la materia prima, formando la salmuera; favorecer la inhibición de bacterias indeseables y contribuir al sabor del producto terminado. Es esencial, por tanto, que su distribución en el producto sea lo mas homogénea posible, razón por la cual algunos fabricantes aprovechan la conducción del material partido a través de la cinta transportadora para la incorporación uniforme al mismo de la sal sólida. Otros, por el contrario, la añaden gradualmente en los tanques de fermentación, de forma alternada con el producto, cuya homogénea distribución debe cuidarse igualmente, favoreciendo asi el cierre de los recipientes y que todo el producto quede, casi desde el principio, cubierto de salmuera, evitando, principalmente, las coloraciones anormales. 
El cierre, casi hermético, puede efectuarse con tejidos plásticos flexibles que se adapten fácilmente a la superficie del próducto, y de forma tal que soportan encima un peso (sólido o líquido) suficiente para mantener las coles, que tienden a flotar, sumergidas en la salmuera.

Al cabo de pocas horas comienza la fermentación que, en condiciones normales, puede completarse en tres o cuatro semanas. Una vez finalizada, el producto está listo para su envasado y pasterización, o para ser comercializado a granel, en barriles, bombonas, etc. Si debe conservarse en los tanques o recipientes mayores citados, por algunos meses, deben vigilarse al máximo las condiciones anaeróbicas, para mantener la calidad del producto, evitando la formación de velos de levaduras y mohos superficiales. La acidez alcanzada al final no debe ser menor del 1,5\%, expresada como ácido láctico, y puede fácilmente llegar al $2 \%$; su composición es una mezcla de ácidos láctico y acético, en una proporción que oscila de 4:1 a 6:1.

Se trata, pues, de un producto fermentado, cuya biotecnología ha sido descrita y puesta al día con detalle por Pederson (1) en una cuidadosa recopilación de sus propios trabajos de investigación anteriores.

Indica este autor que el proceso de fermentación se inicia por la especie Leuconostoc mesenteroides, y continúa con otras especies, regulándose la velocidad del proceso principalmente por la temperatura. Existen, en el protoplasma celular, ciertas sustancias de carácter inhibitorio para el crecimiento de gérmenes y que incluso destruyen algunas bacterias Gram- negativas presentes en el vegetal, siendo este un efecto beneficioso. Insiste en que debe prestarse la máxima atención a la exclusión de aire, control de la sal y a la observación de la relación entre temperatura y velocidad de fermentación.

Las condiciones anaeróbicas eliminan la posibilidad de desarrollo de mohos y levaduras en superficie, y el consiguiente peligro de fenómenos de ablandamiento, oscurecimiento y formación de olores y sabores desagradables. El control de la sal permite buscar el adecuado equilibrio sal/ácido, tan importante para el consumidor y su grado de aceptación del producto final.

Por último, la relación temperatura-velocidad de fermentación está en conexión con la flora microbiana responsable del proceso. Para el autor, es fundamental que no haya un exceso de bacterias lácticas homofermentativas (productoras exclusivamente de ácido láctico), ya que las heterofermentativas, como el Leuconostoc mesenteroides producen, junto con el ácido láctico, ácido acético, que influye decisivamente en el sabor, y anhídrido carbónico, que favorece las condiciones anaeróbicas, muy importantes por las causas apuntadas anteriormente.
Ahora bien, las especies de bacterias lácticas normalmente presentes en la fermentación de coles son, en orden creciente de producción de acidez total, las siguientes:

Streptococcus faecalis (Homofermentativa)

Leuconostoc mesenteroides (Heterofermentativa)

Lactobacillus brevis (Heterofermentativa)

Pediococcus cerevisiae (Homofermentativa)

Lactobacillus plantarum (Homofermentativa)

De ellas, Leuconostoc mesenteroides puede fermentar el producto a baja temperatura $\left(7^{\circ} \mathrm{C}\right)$ y producir una acidez de 0,6 a $0,8 \%$ en menos de un mes. Las especies homofermentativas, Pediococcus cerevisiae y principalmente Lactobacillus plantarum, se desarrollan fácilmente a más alta temperatura $\left(18^{\circ} \mathrm{C}\right)$ y pueden producir una acidez de hasta $1,2 \%$ en pocas semanas, y hasta $1,5 \%$ en $8-10$ dias, si se alcanzan los $23^{\circ} \mathrm{C}$. En este caso, la carencia de producción de anhídrido carbónico resulta en detrimento de la anaerobiosis deseada.

Indica finalmente el autor que, con una fermentación acelerada por la temperatura y consiguiente desarrollo preferente de bacterias lácticas homofermentativas, la acidez presente sería mayoritariamente láctica, con la natural repercusión en las características sensoriales a las que el consumidor está acostumbrado.

Los principales defectos y alteraciones que pueden presentarse en este producto incluyen decoloraciones, oscurecimientos, coloraciones anormales, ablandamiento, viscosidad excesiva de las salmueras, y sabores extraños, atribuibles a fermentaciones secundarias y anormales, o bien a simples reacciones químicas, según los casos.

Pederson hace igualmente referencia a la preparación, por algunas industrias, de un producto muy parecido al que se acaba de tratar, elaborado directamente a partir de coles frescas, por simple acidificación con ácido cítrico y/o vinagre $(0,5-0,7 \%$ de acidez expresada como ácido láctico), endulzadas con azúcar $(5-10 \%)$, aromatizadas con especias, y finalmente pasterizadas.

Stamer (6) sintetiza acertadamente la situación actual de la industria de elaboración de coles ácidas en Estados Unidos de Norteamérica, cuyo volumen alcanza las 200.000 toneladas de coles elaboradas según esta especialidad, y suministra datos muy interesantes sobre la recolección mecánica, que permite efectuar ésta a una velocidad de 7 a 14 toneladas/hora; las capacidades de los tanques de fermentación, de 20 a 70 toneladas los antiguos de madera, y hasta 180 toneladas los de hormigón revestido; y la vida de mercado del producto pasterizado, que oscila entre 12 meses, para recipientes de vidrio, y 18-30 meses para las latas barnizadas. 
Indica igualmente este autor que puede conservarse el producto de 8 a 12 meses en bolsas de plástico, refrigeradas a $5^{\circ} \mathrm{C}$, mediante aditivos químicos, estando autorizado el uso de benzoato sódico al $0,1 \%$ en peso, y de metabisulfito potásico, con una concentración de $\mathrm{SO}_{2}$ según requiera la práctica de buena fabricación.

Su descripción del proceso fermentativo ratifica, en general, las conclusiones establecidas por Pederson, añadiendo interesantes comentarios sobre los posibles defectos de coloración que pueden encontrarse en el producto final por la acción de levaduras y bacterias.

En el esquema 1 se compendian las fases de la elaboración y comercialización del producto fermentado en Estados Unidos de Norteamérica, destacándose los rasgos fundamentales de cada una de ellas.

\section{PEPINILLOS}

Entre los yegetales destinados a conservas, los pepinillos ocupan actualmente el cuarto lugar en Estados Unidos de Norteamérica (6), con una producción alrededor de las 700.000 toneladas (7) y un valor estimado en más de ciento veinte millones de dóla- res. Constituye, por tanto, la cosecha más importante destinada en dicho país a la elaboración de vegetales aderezados, y recibe atención preferente por parte de países tales como Francia, Canadá, Holanda, Inglaterra y Suiza en cuanto a consumo (8).

Planta que requiere cultivos templados, $\theta$ incluso semitropicales, cuyo enemigo fundamental lo constituyen las heladas y sequias, presenta en España su principal zona de cultivo en las regiones de La Rioja, Navarra, Levante, Cataluña, Baleares, Extremadura y León. Andalucía, que tiene unas condiciones climáticas adecuadas para su explotación, no ha prestado atención especial a este cultivo hasta hace pocos años. La producción española, del 3 al $5 \%$ de la norteamericana, ha ido adquiriendo una calidad muy aceptable aunque, quizás por falta de adaptación al gusto del consumidor, la expansión de su consumo no ha alcanzado rápidamente las cotas deseables (9).

Descripciones detalladas del proceso han sido realizadas por Vaughn (5), Cruess (3) y Pederson (1), y más recientemente por Stamer (6). En ellas se compendian los excelentes trabajos de Fabián, Costilow, Etchells, Fleming y otros investigadores, que han contribuido en los últimos cincuenta años a desarrollar la tecnología de la que actualmente se dispone.

ESQUEMA 1.- COLES ACIDAS.- Características de la industria norteamericana, según Stamer (6).

A.- Preparación y fermentación:

FASE.

RASGOS FUNDANERTALES.

\begin{tabular}{|c|c|}
\hline COLES FRESCAS. & 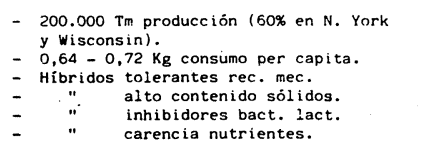 \\
\hline RECOLECCION. & $\begin{array}{l}\text { - E1 97\% rec. mec. en } \mathrm{N} \text {. York. } \\
\text { - Velocidad: } 7-14 \mathrm{Tm} / \mathrm{hora} \text {. }\end{array}$ \\
\hline CLASIFICACION. & $\begin{array}{l}\text { - Control enfermedades e insectos. } \\
\text { - Forma y textura de los repollos. } \\
\text { - Tamaño (minimo } 14 \mathrm{~cm} \text { diámetro). } \\
\text { - Longitud del corazón. } \\
\text { - Presencia manchas y defectos int. } \\
\text { - Proporción hojas de desecho. }\end{array}$ \\
\hline ELIMINACION DE HOJAS. & - Máquinas de rodillos. \\
\hline DESCORAZONADO. & - Taladros o barrenas verticales. \\
\hline LIMPIEZA. & $\begin{array}{l}\text { - Eliminación manual de hojas verdes. } \\
\text { - Al final de esta fase, se ha eliminado } \\
\text {. del } 26 \text { al } 42 \% \text { de mat. prima. }\end{array}$ \\
\hline CORTADO EN TIRAS. & $\begin{array}{l}\text { - Troceador mecánico de cuchillas. } \\
\text { - Veiocidad: } 8-10 \mathrm{Tm} / \mathrm{hora} \text {. }\end{array}$ \\
\hline SALADO. & $\begin{array}{l}\text { - No menos del } 2 \% \mathrm{NaCl} \text { ni mas del } 3 \% . \\
\text { - Extrae jugo celular. } \\
\text { - Inhibe gérmenes indeseables. } \\
\text { - Contribuye a textura, olor } y \text { sabor. } \\
\text { - Relación ácido/sal: } 1 / 1,3\end{array}$ \\
\hline FERMENTACION. & $\begin{array}{l}\text { - Recipientes madera: } 20-70 \mathrm{Tm} \\
-\quad \text { hormigon: } 180 \mathrm{Tm} \\
\text { - Bacterias Gram negativas: lä́cticas homo y } \\
\text { heterofermentativas. } \\
\text { - Baja capacidad tarión. }\end{array}$ \\
\hline
\end{tabular}

B.- Fase de comercializaciōn:

PROCEDIMIENTO ALTERNATIVO. RASGOS FUNDAMENTALES.

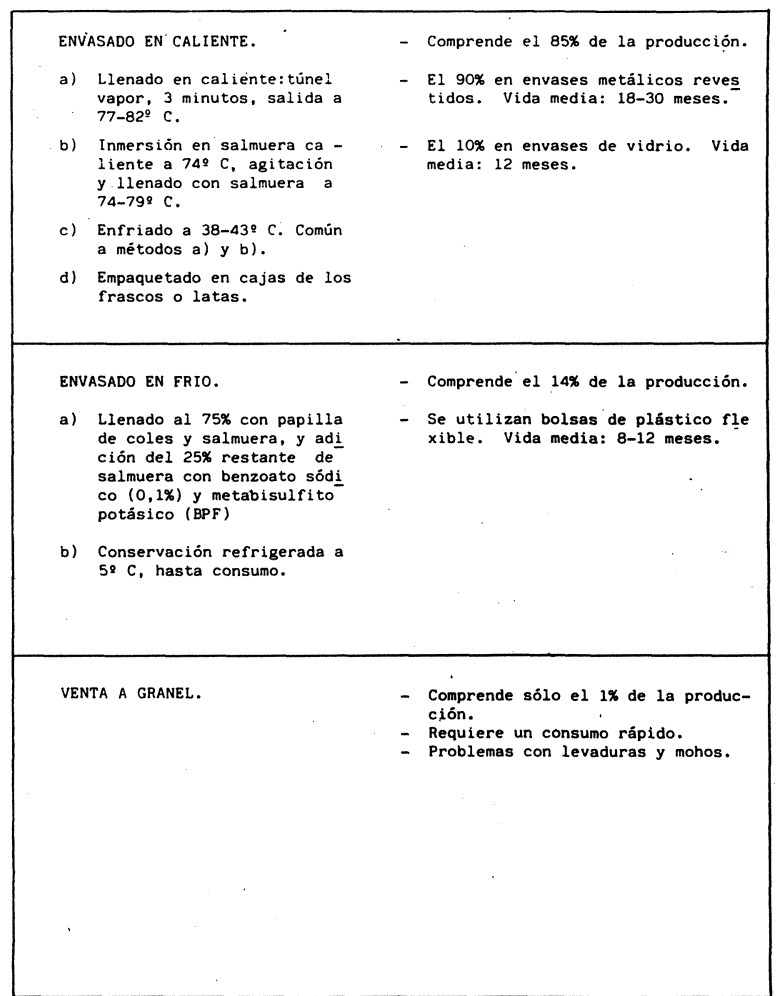


Se han conseguido nuevas variedades que, actualmente, producen frutos de tamaño, forma, color $y$ textura más uniforme, y que pueden adaptarse fácilmente a la recolección mecánica que, por ejemplo, en el estado de Michigan, alcanzó en los últimos años el $90 \%$ de la cosecha.

Los frutos, una vez recolectados, se transportan rápidamente a la fábrica para evitar daños, principalmente debidos a la población microbiana que les acompaña; se seleccionan, eliminando los dañados, deformes, etc. La clasificación previa por tamaños, según diámetros, es opcional, verificándose con frecuencia después de la fermentación.

En cuanto al proceso de elaboración, se pueden hacer dos grandes grupos: pepinillos curados, por fermentación y conservación en salmuera, y envasados en fresco, esto es, aderezados directamente después de la recolección, sin someterlos al referido proceso de fermentación. Aún cuando el primer tipo ha sido el principal durante muchos años, recientemente los preparados aderezando directamente los frutos frescos han recibido, por parte del consumidor, una aceptación tal que, en la actualidad, las ventas se reparten entre ambos grupos de forma bastante equilibrada ( $40 \%$ por fermentación y $60 \%$ mediante otras preparaciones).

Para la fermentación, los frutos se han colocado tradicionalmente en tanques de madera, recubiertos de tablas del mismo material, con una salmuera de alrededor del $10 \%$ de cloruro sódico, con circulación periódica del líquido y adiciones sucesivas de sal, hasta alcanzar al final valores incluso del $15 \%$ de sal. Variaciones múltiples se han producido a lo largo del tiempo, en cuanto a capacidad, forma y tipo de material de los tanques de fermentación, así como en relación al tipo de cierre y grado de anaerobiosis.

La flora microbiana desarrollada es muy diversa, como en el caso de las coles ácidas, pero por utilizarse en general en este caso concentraciones de sal superiores, la secuencia puede ser totalmente distinta dependiendo, por supuesto, además de otros factores, principalmente de la temperatura, composición del medio y grado de anaerobiosis o aerobiosis mantenido durante el proceso.

Etchells y Jones (10) describen tres grupos de microorganismos presentes: bacterias coliformes, bacterias lácticas y levaduras. Algunas de las coliformes pueden producir abundantes gases $\left(\mathrm{H}_{2}\right.$ y $\left.\mathrm{CO}_{2}\right)$ y ser responsables de alteraciones importantes en la estructura de los frutos, similares a las encontradas en las aceitunas verdes de mesa, y conocidas como ampollado, vejigas, anillado y alambrado. Un control del valor de $\mathrm{pH}$, mediante la correspondiente acidificación inicial de la salmuera, da buenos resultados para la rápida eliminación de estos gérmenes (8).

Entre las bacterias lácticas principalmente desarrolladas citan Lactobacillus plantarum, L. Brevis y
Pediococcus cerevisiae, el segundo de los cuales es heterofermentativo, como se ha indicado anteriormente. A diferencia de las coles ácidas, el Leuconostoc mesenteroides no es aquí frecuente por las concentraciones de sal que se emplean generalmente. Las levaduras superficiales, de metabolismo oxidativo, pueden conducir a problemas de ablandamiento y a pérdidas importantes de la cantidad de ácido producido por las bacterias lácticas durante la fermentación; entre las levaduras fermentativas, algunas especies pueden ser también causantes de pérdida de textura e incluso de las alteraciones gaseosas indicadas anteriormente.

Etchells y colbs. (11) (12) aconsejan una fermentación controlada, mediante acidificación e inoculación con bacterias lácticas homofermentativas, purgando los tanques de fermentación (de materiales plásticos) con nitrógeno, para eliminar el $\mathrm{CO}_{2}$ producido y evitar así la alteración gaseosa. Posteriormente, Fleming (13), Costilow y colbs. (14), Costilow y Uebersax (15) y Durán Quintana y colbs. (16) han sustituido el nitrógeno por aire, también con buenos resultados; Fleming y colbs (7) (17) (18) desarrollan un tanque anaeróbico para la fermentación, y en él emplean de nuevo la purga con nitrógeno.

Rodrigo y colbs. (19) realizan recientemente una excelente revisión de los conocimientos actuales sobre las condiciones de cultivo, características, composición química y prealmacenamiento de pepinillos, así como sobre las condiciones de fermentación y envasado de los mismos. En España se producen actualmente unas $17.000 \mathrm{Tm}$., exportándose principalmente a la CEE, Canadá y Estados Unidos de Norteamérica.

Los genuinos pepinillos al eneldo, "dill pickles", son también muy populares; varian fundamentalmente de los descritos en dos aspectos: que se fermentan en presencia de dicha planta aromatizante (Anetum graveolens) de la familia de las umbelíferas y de otras especias, y en que se utiliza para el proceso tradicionalmente una concentración de sal inferior, con lo cual es frecuente, en las primeras fases, la presencia de Leuconostoc mesenteroides, al igual que en las coles ácidas.

Los múltiples productos preparados a partir del fruto fresco, esto es, sin fermentación previa, incluyen los llamados ácidos, con una elevada dosis de vinagre; los dulces, con cantidades variables de azúcar añadido y los aromatizados, con eneldo y otras especias, así como las mezclas de elaboraciones citadas, dependiendo su volumen de comercialización de la demanda del consumidor. Su conservación se realiza, generalmente, mediante pasterización, o bien por aditivos químicos, como el benzoato sódico al $0,1 \%$ y conservación a temperatura reducida, entre 4 y $7^{\circ} \mathrm{C}$ método que no proporciona tan buenos y seguros resultados como el procedimiento térmico. 
El producto final envasado que, frecuentemente, se distribuye en los mercados europeos (8) presenta valores de $\mathrm{pH}$ que oscilan entre 3,1 y 3,95 unidades; una acidez libre, principalmente acética, del 0,87 al $3,87 \%$; un contenido en cloruro sódico del 1,2 al $5 \% \mathrm{y}$, en el caso de los agridulces, alrededor del $8-10 \%$ de azúcares solubles.

Las principales alteraciones y defectos que pueden producirse durante la elaboración y conservación de pepinillos son análogos, en causas y efectos, a los descritos para las coles ácidas, e incluyen por tanto, además de la alteración gaseosa indicada anteriormente, problemas de ablandamiento, viscosidad de frutos y salmueras, olores, sabores y coloraciones anormales.

En el esquema 2 se resumen las fases de la elaboración y los procedimientos de conservación, destacándose los rasgos fundamentales de cada fase 0 método.

ESQUEMA 2.- PEPINILLOS. Características de la industria norteamericana, según Stamer (6) y Fleming y colbs. (7).

A.- Preparación y Fermentación:

FASE.

RASGOS FUNDAMENTALES.

\begin{tabular}{|c|c|}
\hline PEPINILLOS FRESCOS. & $\begin{array}{l}\text { - } 700.000 \mathrm{Tm} \text { producción (50\% en Michigan, } \\
\text { Carolina del Norte, Ohio y California) } \\
\text { - } 3,6 \mathrm{Kg} \text { consumo per capita. } \\
\text { - } 40 \% \text { por fermentación y } 60 \% \text { acondiciona } \\
\text { do en fresco. } \\
\text { - Variedades: Pioneer, Carolina, Calipso, } \\
\text { Calico, Regal y Explorer. } \\
\text { - En general, variedades con pinchos, vi- } \\
\text { gorosas y sin amargor. } \\
\text { - Hibridos resistentes a virus y adapta - } \\
\text { bles a rec. mecánica. }\end{array}$ \\
\hline RECOLECCION. & $\begin{array}{l}\text { - El } 90 \% \text { de recolección mecánica en } \mathrm{Mi} \text { - } \\
\text { chigan. }\end{array}$ \\
\hline CLASIFICACION. & $\begin{array}{l}\text { - Eliminación de frutos dañados y malfor } \\
\text { mados. } \\
\text { - Clasificación por tamaños es opcional. }\end{array}$ \\
\hline COLOCACION EN SALMUERA. & $\begin{array}{l}\text { - Tradicionalmente del } 10 \% \\
\text { - Recirculación. } \\
\text { - Incremento conc. sal, a veces hasta el } \\
\text { - Tendencia a bajas conc. de sal. }\end{array}$ \\
\hline FERMENTACION. & $\begin{array}{l}\text { - Tanques tradicionales de madera, 2,5-25 } \\
\text { Tm } \\
\text { - Tanques actuales, 19-38 Tm } \\
\text { - Otros materiales: hormigón revestido, } \\
\text { poliester, etc. } \\
\text { - Inoculación cultivos puros de bact. } \\
\text { lácticas homofermentativas. } \\
\text { - Purga de } \mathrm{CO}_{2} \\
\text { - Bacterias Gram negativas. } \\
\text { - Bacterias lácticas homo y heterof. } \\
\text { - Levaduras. }\end{array}$ \\
\hline
\end{tabular}

\section{PIMIENTOS}

Dentro de las diversas formas de presentación de las aceitunas verdes aderezadas, estilo español o sevillano, las rellenas de pimiento han ocupado una posición realmente excepcional y predominante en la exportación española de aceitunas de mesa, como indica el hecho de que, al comienzo de la década de los setenta, se consumían en España anualmente en este menester, entre 10.000 y 20.000 toneladas de fruto elaborado del género Capsicum.

Si bien, por razones económicas, en la actualidad el uso del pimiento como tal ha sido desplazado casi en su totalidad por la denominada cinta o aglutinado de pimiento, para cuya fabricación se parte de un triturado del fruto, conservado y comercializado en envases metálicos, empleando en su preparación una tecnología análoga a la del concentrado de tomate,
B.- Fase de comercialización:

PROCEDIMIENTO DE CONSERVACION. RASGOS FUNDANENTALES.

\begin{tabular}{|c|c|c|}
\hline \multicolumn{2}{|c|}{ PASTER IZAC ION. } & \multirow[t]{5}{*}{$\begin{array}{l}\text { - Sistema de conservación más } \\
\text { estable. }\end{array}$} \\
\hline a) & Desalado (si fermentado) & \\
\hline b) & $\begin{array}{l}\text { Adición condimentos y espe - } \\
\text { cias. }\end{array}$ & \\
\hline c) & $\begin{array}{l}\text { Pasterización a } 78,3^{\circ} \mathrm{C} ., 15 \\
\text { minutos. }\end{array}$ & \\
\hline d) & Enfriado. & \\
\hline \multicolumn{2}{|c|}{ REFRIGERACION. } & $\begin{array}{l}\text { - Da resultados menos seguros } \\
\text { que el anterior. }\end{array}$ \\
\hline a) & Desalado (si fermentado) & \\
\hline b) & $\begin{array}{l}\text { Adición condimentos, especias } \\
\text { y benzoato sódico al } 0,1 \%\end{array}$ & \\
\hline c) & $\begin{array}{l}\text { Conservación refrigerada a } \\
4-70 \mathrm{C} \text {. }\end{array}$ & \\
\hline
\end{tabular}

creemos conveniente revisar su elaboración como producto aderezado fermentado, ya que las investigaciones tecnológicas, realizadas en la época a que aludíamos anteriormente, reivindican un papel importante a tener en cuenta para un grupo de microorganismos, las levaduras, que en otros productos aderezados se consideran sin valor, e incluso en ocasiones como perjudiciales.

Tradicionalmente, el pimiento para el relleno se había preparado en España colocando los frutos, pelados en horno, a llama directa de fuel oil, en barriles de madera, con capas alternas de sal, recubriéndolos con salmuera saturada y manteniéndolos de esta forma hasta el momento de su empleo en las operaciones de relleno. El procedimiento, simple conservación más que fermentación, si bien comunicaba al producto unas buenas características sensoriales, posiblemente por la acción de ciertas levaduras halófilas, tenía el incon- 
veniente de mantener alta la concentración de azúcares, incluso después de muchos meses de conservación, con la consiguiente posibilidad de fermentación posterior en la aceituna rellena, envasada en concentraciones moderadas de cloruro sódico.

Aligizaki realiza en Grecia un estudio práctico que consiste en fermentar los pimientos, pelados con hidróxido sódico y lavados posteriormente con agua - salmuera acidulada, en una salmuera de más baja graduación, alrededor del $10 \%$ de $\mathrm{NaCl}$, con control de $\mathrm{pH}$, alrededor de 3 a 3,4 unidades, mediante adición de ácido láctico, en condiciones de anaerobiosis, para evitar el desarrollo de mohos y levaduras superficiales, y atribuye a ciertas levaduras fermentativas, del género Saccharomyces, las excelentes características organolépticas del producto obtenido (20).

Investigaciones posteriores de Mínguez Mosquera y colbs. (21) confirman que este procedimiento, utilizando, concentraciones de sal entre 10 y $13 \%$ de $\mathrm{NaCl}$, y valores controlados de $\mathrm{pH}$ entre 3 y 4 unidades, da lugar a un producto final de buena textura, que evita la presencia de materia fermentable en la aceituna rellena, y se demuestra que las levaduras son los microorganismos responsables de la fermentación. La presencia de bacterias lácticas se considera, en este caso, accidental. González Cancho y colbs. (22) identifican en el proceso de fermentación espon- tánea, $\infty$ mo especies más representativas, las siguientes: Hansenula subpelliculosa, Saccharomyces lactis, $H$. anómala, S. roxii, Hanseniaspora valbyensis, y $\mathrm{S}$. cerevisiae, entre las esporígenas, y Candida Krusei, Kloeckera apiculata y Torulopsis famata, entre las no esporígenas.

Minguez Mosquera y colbs. (23) realizan posteriores ensayos de fermentación dirigida con algunas de las especies aisladas, estudiándose por cromatografía gaseosa (24) los aromas producidos durante el proceso, $\theta$ identificando, entre los principales componentes, acetaldehido, acetona, acetato de etilo, propanol-2, etanol, propanol-1, 2-metil-propanol-1, butanol-1, y 3-metil-butanol-1.

González Cancho y colbs. (25) recopilan los resultados de estas investigaciones, llegando a las siguientes conclusiones:

a).- La fermentación espontánea por levaduras del pimiento, en salmuera de baja graduación, constituye un proceso de elaboración que permite la rápida eliminación de la materia fermentable en tres fases, perfectamente definidas. En la primera, se produce un descenso rápido de la concentración de azúcares reductores, que alcanza al $60-70 \%$ de los presentes; la segunda fase termina cuando el total de azúcares fermentados es, aproximadamente, del $85 \%$; y finalmente la tercera, dura hasta la eliminación total de

ESquEMA 3.- OTROS FRUTOS Y VEgetales ADEREZAdos.- Fases de la elaboración y métodos de conservación.

A.- Preparación y fermentación:

FASE.

OBSERVACIONES.

\begin{tabular}{|c|c|}
\hline MATERIA PRIMA. & $\begin{array}{l}\text { - Variedad resisterite a plagas y enfer } \\
\text { - medades. } \\
\text { - Facilidad de cultivo. } \\
\text { - Presencia de inhibidores y nutrien - } \\
\text { tes. } \\
\text { - Adaptación a rec. mecánica. }\end{array}$ \\
\hline RECOLECCION. & - Mecánica, si posible. \\
\hline LAVADO: & $\begin{array}{l}\text { - Necesario, sobre todo, en caso de tu- } \\
\text { bérculos. }\end{array}$ \\
\hline CLASIFICACION. & $\begin{array}{l}\text { - Tamaños (cebollas y remolachas). } \\
\text { - Forma y textura, hojas (coliflores). } \\
\text { - Defectos internos. }\end{array}$ \\
\hline $\begin{array}{l}\text { DESCORAZOMADO Y ELIMINA- } \\
\text { CION DE HOJAS. }\end{array}$ & - Coliflores. \\
\hline ESCALDADO. & - Remolachas. \\
\hline PELADO. & - Remolachas, cebollas. \\
\hline LIMPIEZA. & $\begin{array}{l}\text { - Remolachas, después de escaldado y } \\
\text { pelado. }\end{array}$ \\
\hline SEGUNDA CLASIFICACION. & - Remolachas y cebollas. \\
\hline CORTADO. & - Remolachas y coliflores. \\
\hline SALADO. & $\begin{array}{l}\text { Si se procede a fermentación o conser } \\
\text { vación en salmuera. }\end{array}$ \\
\hline ACONDICIONAMIENTO. & - Si se pasa a fase de comercialización. \\
\hline FERMENTACION. & $\begin{array}{l}\text { - Cebollas, coliflores, alcaparras y } \\
\text { alcaparrones. } \\
\text { - Bacterias Gram negativas, lácticas } \\
\text { hetero y homofermentativas. }\end{array}$ \\
\hline
\end{tabular}

B.- Fase de comercialización:

PROCEDIMIERTO DE CONSERVACION.

RASGOS FUMDANGNTALES.

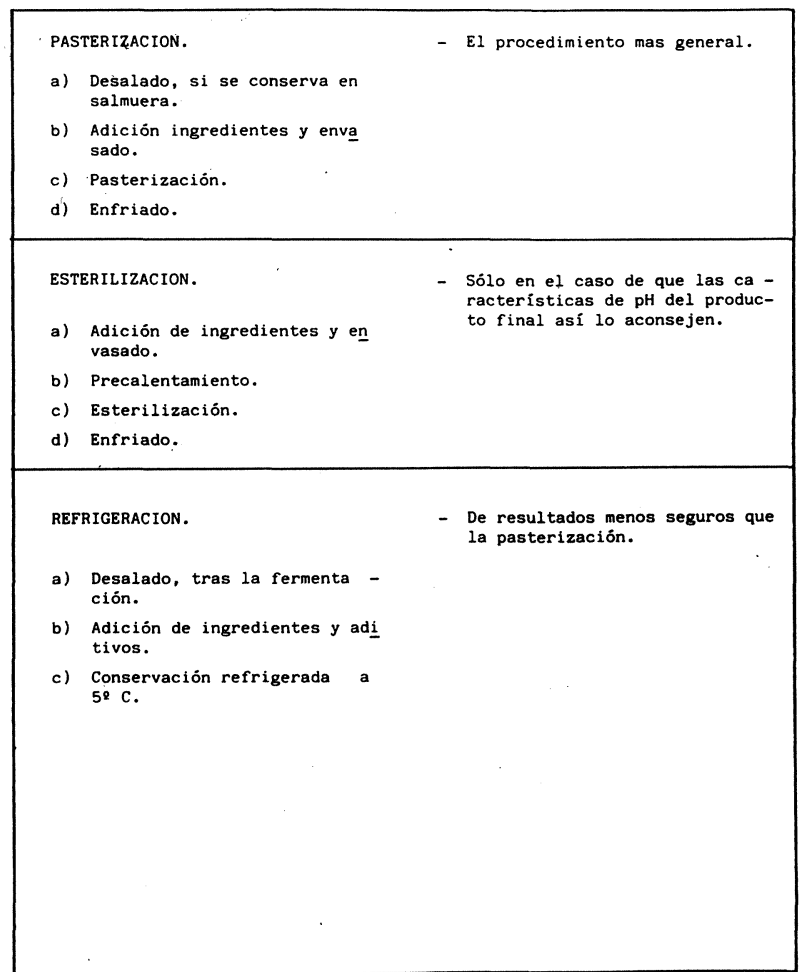


la materia fermentable. La duración del proceso, en condiciones óptimas, puede estimarse entre 20 y 30 dias, aproximadamente.

b).- Este producto hace que los frutos mantengan una buena textura durante largo tiempo, y permite el empleo de unos medios de control (valor de $\mathrm{pH}$, contenido en cloruro sódico y anaerobiosis) sumamente simples desde el punto de vista tecnológico, presentando, por consiguiente, ventajas económicas destacadas, con respecto al método tradicional de conservación en salmuera saturada.

c).- En relación con el posible empleo de las distintas especies de levaduras ensayadas en la fermentación dirigida y su repercusión en la calidad del producto final fermentado, prácticamente todas la especies ensayadas cumplen las condiciones de consumo rápido de azúcares y proporcionan unas caracteristicas sensoriales finales muy aceptables, así como buena textura.

Sin embargo, considerando que Hansenula subpelliculosa tiene las ventajas de su elevada supervivencia y de producir mayor cantidad de productos volátiles, frente al inconveniente de una eliminación muy lenta de la materia fermentable, puede ser recomendable su uso, juntamente con alguna de las especies de Saccharomyces o Kluyveromyces, caracterizadas por el rápido consumo de azúcares.

\section{OTROS FRUTOS Y VEGETALES ADEREZADOS.}

Del resto de los productos aderezados, los de mayor relevancia en relación con su producción actual y perspectivas de mercado, son la alcaparra y alcaparrón, cebollita, coliflor y remolacha. Su tecnología, muy similar a las descritas, está por desarrollar en múltiples aspectos, y no ha despertado aún adecuadamente el interés de los investigadores, por la relativamente reducida importancia de su comercialización actual. Las fases de su preparación y procedimientos de conservación, variables según países e industrias, se puede resumir de acuerdo con el esquema 3.

\section{ORIENTACIONES PARA LA INVESTIGACIÓN $Y$ DESARROLLO EN LA INDUSTRIA DE ADEREZO Y FERMENTACIÓN DE FRUTOS $Y$ VEGETALES.}

Analizados los procesos tecnológicos correspondientes a los frutos y vegetales aderezados que mayor impacto han producido y continúan produciendo en el mercado internacional, se hacen algunas consideraciones, que pueden ser de utilidad para fijar las metas futuras de la investigación aplicada en este área de la Tecnología de Alimentos:
-Coincidimos plenamente con Pederson (1) y Fleming (26) al afirmar que, casi todos los vegetales y frutos pueden, en principio, conservarse por medio de una fermentación en salmuera, llevada a cabo por bacterias lácticas y/o levaduras. La facilidad y rentabilidad de la operación, dependerá de la materia fermentable que contenga el vegetal fresco, así como de la presencia o ausencia de suficientes nutrientes y de inhibidores naturales.

- La importancia de este sistema de preparación y conservación de alimentos radica en varios hechos fundamentales: a) permite la elaboración de productos con características sensoriales muy especiales y definidas, mayoritariamente aceptadas por un mercado consumidor amplio, no sólo como alimento en sí, sino como aperitivo selecto, complemento de delicados menús y bebidas alcohólicas tipicas; b) permite, igualmente, la conservación durante largo tiempo de materias primas, para ser preparadas finalmente cuando el mercado lo demande, y evitando así las dificultades, a veces insalvables, de elaborar grandes cosechas, dentro del reducido intervalo de tiempo que marca el periodo de recolección; c) constituye un medio de elaboración de bajo consumo de energía, puesto que, por las características finales del producto, bajo valor de $\mathrm{pH}$ y acidez relativamente alta no requiere, en una gran parte de los casos, proceso térmico alguno, y todo lo más, una simple pasterización es suficiente, en lugar de una esterilización; y d) como consecuencia del hecho anterior, se retienen mas fácilmente en el producto los nutrientes, algunos de ellos lábiles al calor, y se mantienen mejor determinadas propiedades físicas, tan importantes como el felor y la textura.

-En el orden secuencial, dictado por la Naturaleza, preceden, generalmente, a las bacterias lácticas, las aerobias Gram negativas, frecuentemente presentes en los propios vegetales, en el agua, etc., productoras en muchos casos de alteraciones gaseosas, pero que, $\in n$ ciertos aspectos, preparan naturalmente, con un moderado descenso inicial del valor de $\mathrm{pH}$ del medio, el camino a sus sucesoras.

-Por lo que respecta a las bacterias lácticas, principales responsables de la mayor parte de las fermentaciones indicadas, puede señalarse que corresponden a un número de especies muy limitado, especies que, naturalmente, tienden a desarroliarse siempre de una manera secuencial comenzando, en muchos casos, por un predominio de bacterias homofermentativas (productoras de $\mathrm{CO}_{2}$, ácido acético y ácido láctico), y siguiéndoles las homofermentativas, generadoras exclusivamente de ácido láctico.

-En este orden secuencial, las bacterias lácticas heterofermentativas, con el $\mathrm{CO}_{2}$ producido, contribuyen, por un lado, a la creación de un grado de anaerobiosis que evita que continúe el desarrollo de las aerobias Gram negativas, estabilizan el ácido 
ascórbico presente, y el color de los frutos o vegetales, disminuyendo el potencial de oxido-reducción del medio $y$, por otro lado, facilitan, con un más acusado descenso del valor de $\mathrm{pH}$, el desarrollo de las bacterias lácticas homofermentativas, productoras exclusivas de ácido láctico, como decíamos anteriormente, y vehículos, por tanto, necesarios para alcanzar valores de $\mathrm{pH}$ verdaderamente efectivos para la conservación natural del producto.

Las bacterias lácticas heterofermentivas presentan, por el contrario, el inconveniente de disminuir, en muchos casos, el rendimiento de la materia fermentable, cuando la acidez que se desea en el producto final es predominantemente y fundamentalmente láctica.

- Las levaduras fermentativas, acompañantes casi o totalmente omnipresentes de las bacterias lácticas en el proceso natural, y predominantes en algunos casos según los factores condicionantes, si bien a veces pueden ser responsables de fenómenos de ablandamiento, coloraciones anormales, o fermentaciones gaseoseas indeseables, en ciertas preparaciones pueden llegar a ser las protagonistas principales de una fermentación que, adecuadamente desarrollada y controlada, da lugar a productos de características sensoriales muy apreciadas por el consumidor.

- La presencia accidental de mohos y levaduras oxidativas superficiales, si no existen condiciones adecuadas de anaerobiosis, y la acción de diferentes especies de los géneros Clostridium y Propionibacterium, si no se evita su desarrollo con el adecuado control, pueden dar lugar a alteraciones importantes de ablandamiento, malolientes, etc.

-Estos papeles fundamentales que cada microorganismo tiene asignados en la Naturaleza, pueden ser modificados o sustituidos, parcialmente por la tecnología, variando las condiciones ambientales, en lo que respecta a un número muy limitado de factores que son los siguientes:

- Valor de pH del medio

- Acidez libre

- Acidez combinada (capacidad tampón)

- Contenido de cloruro sódico

- Temperatura

- Grado de aerobiosis o anaerobiosis

- Empleo de cultivos puros como iniciadores del proceso

- Prueba evidente de la eficacia de la consideración anterior se encuentra en la difusión y aceptación de los productos aderezados por acidificación que, partiendo de las mismas materias primas utilizadas para la fermentación, presentan grandes analogías, y en algunos casos importantes ventajas económicas, con respecto a sus homólogos biopreparados.
- Para poder aplicar correctamente, en cada momento y en cada producto, estas modificaciones tecnológicas, la ayuda básica y fundamental que debe aportar la investigación es la siguiente:

1.- Conocimiento, lo mas amplio posible, de la composición química del vegetal o fruto objeto del estudio.

2.- Idem del orden secuencial, natural y específico, de los microorganismos desarrollados en el producto a investigar.

3.- Selección de variedades aptas como materia prima.

4.- Fijación de los intervalos óptimos de recolección.

Con estas herramientas de trabajo, y no más, cualquier producto vegetal aderezado es, en principio, posible y puede ser comercialmente aceptable. En las manos del científico y tecnólogo existe todavía un potencial ilimitado de recursos vegetales por explotar, para resolver las necesidades y dificultades de la alimentación futura.

\section{BIBLIOGRAFIA}

1. Pederson, C. S.- "Pickles and Sauerkraut" in "Commercial Ve getab!e Processing" pp 457-490.- B. S. Luh and J. G. Woodroo (Eds). The AVI Publishing Co. Inc., Westport, Conn., U.S.A. 1975.

2. Luh, B.S. and York, G.K.- "General Principles and Methods" in "Commercial Vegetable Processing" pp 1-32.- B.S. Luh and J. G. Woodroof (Eds.). The AVI Publishing Co. Inc., Westport, Conn. U.S.A., 1975

3. Cruess, W.V.- "Commercial Fruits and Vegetable Products".4th Ed..- McGraw - Hill Book Co. Inc. New York, 1958

4. Woodroof, J. G.- "Pickled Fruits" in "Commercial Fruit Processing" pp 447-496.- J. G. Woodroof and B. S. Luh (Eds.), The AVI Publishing Co. Inc., Westport, Conn., U.S.A., 1975

5. Vaughn, R. H..- "Lactic Acid Fermentation of Cucumbers, Sauerk raut and Olives" in "Industrial Fermentation" Vol. II, pp 417-478. L. A. Underkofler and R. J. Hickey (Eds.), Chemical Publishing Co. Inc., New York, 1954.

6. Stamer, J. R.- "Lactic Acid Fermentation of Cabbage and Cu cumbers" in "Biotechnology", Vol. 5, pp. 365-378.- H. J. Rehm and G. Reed (Eds.), Verlag Chemie, Weinheim, RFA, 1983.

7. Fleming, H. P., McFeeters, R. F., Daeschel, M. A., Humphries, E. G. and Thomson, R. L.- "Fermentation of cucumbers in anaerobic tanks".- J. Food Sci. 53 (1988) 127-133.

8. González Pellissó, F.; Rejano Navarro, L.; Durán Quintana, M C. y Fernández Diez, M. J.- "El empleo del ácido láctico en la elaboración de pepinillos".- Grasas y Aceites 31 (1980) 13-21.

9. Rodrigo, M.; Durán, L.; Cuñat, P.; Fuster, V. y Portela, E"Especificaciones del proceso de fabricación de encurtidos' de pepinillos". - Información de resultados n.? 48. Instituto de Agroquimica y Tecnologia de Alimentos. Valencia, 1968.

10. Etchells, J. L. and Jones, I. D.- "Bacteriological changes in cucumber fermentation".- Food Ind. 15 (1943) 54-56.

11. Etchells, J. L.; Bell, T. A.; Fleming, H. P.; Kelling, R. E. and Thomson, R. L.- "Suggested procedure for the controlled fermentation of commercially brined pickling cucumbers. The use of starter cultures and reduction of carbon dioxide accumulation".- Pickle Pak Sci. 3 (1973) 4-14. 
12. Etchells, J. L., Fleming, H. P. and Bell, T.A.-"Factors influencing the growth of lactic acid bacteria during brine fermentation of cucumbers" in "Lactic acid bacteria in beverages and food" pp 281-305.- Carr, J. G., Cutting C. V. and Whiting, G. C. (Eds.), Academic Press, New York, 1975.

13. Fleming, H. P.- "Purging carbon dioxide from cucumbers to prevent bloater damage. A review".- Pickle Pak Sci. 6 (1979) 8-22.

14. Costilow, R. N.; Gates, K. and Bedford C. L.- "Air purging of commercial salt-stock pickle fermentation".- J. Food Sci. 46 (1981) 278-282.

15. Costillow, R. N. and Uebersax, M.- "Effects of various treatments on the quality of salt-stock pickles from commercial fermentations purged with air".- J. Food Sci. 47 (1982) 1866-1868.

16. Durán Quintana, M. C.; Garrido Fernandez, A. y Garcia Garcia P.- "Ensayos de modificación de la fermentación tradicional de pepinillos para evitar la aparición de cavidades interiores".Grasas y Aceites 36 (1985) 193-197.

17. Fleming, H. P., Humphries, E. G. and Macon, J. A.-- "Progress on development of an anaerobic tank for brining of cucumber."Pickle Pak Sci. 7 (1983) 3-15

18. Fleming, H. P.; Daeschel. M.A.; McFeeters, R.F. and Pierson M.D..- "Butyric acid spoilage of fermented cucumbers".- J. Food Sci. 54 (1989) 636-639.

19. Rodrigo, M,: Martinez, A.; Alvarruiz, M.; Lázaro, J.; Fernández M. y Navarro, A.- "Estado actual y avances en la conservación de pepinillos por fermentación"- Rev. Agroquim. Tecnol. Aliment. 24 (1984) 453-466.

20. Fernández Diez M.J.- "Elaboración de aceitunas de mesa en Grecia".- Grasas y Aceites 20 (1969) 12-24

21. Minguez Mosquera, M.I.; González Cancho, F.: Pérez Paz, C.M. Marquez González, J. y Fernández Diez, M.J..- "Elaboración de pimiento para el relleno de aceitunas. Pelado quimico y conservación en salmuera de baja graduación. II. Resultados de la campaña 1969-70".- Grasas y Aceites 21 (1970) 342-348.

22. González Cancho, F.; Minguez Mosquera, M.I. y Fernández Diez, M.J..- "La fermentación del pimiento empleado en el relleno de aceitunas verdes".- Microbiol. Españ. 25 (1972) 81-90.

23. Minguez Mosquera, M.I.; Nosti Vega, M.; González Cancho, F y Fernández Diez, M.J.- "Elaboración del pimiento para el relleno de aceitunas. Pelado químico y conservación en salmuera de baja graducación. III. Resultados de las campañas 1970-71 y 1971-72".- Grasas y Aceites 24 (1973) $1-10$

24. Nosti Vega, M. y Fernández Quintana, G.- "Identificación por cromatografía gaseosa de los componentes volátiles producidos en la fermentación del pimiento para el relleno de aceitunas". Grasas y Aceites 26 (1975) 369-377.

25. González Cancho, F; Nosti Vega, M; Minguez Mosquera, M.I y Fernández Diez, M.J.- "Estudio de las fases de la fermentación del pimiento empleado en el relleno de aceitunas".- Grasas y Aceites 26 (1975) 63-72.

26. Fleming, H.P.- "Fermented vegetables" in "Economic Microbio logy. Fermented Foods". Vol. 7, pp 227-258.- A.H. Rose (Ed), Academic Press, Inc. New York, 1982.

(Recibido Junio 1990) 